\title{
An Overview of Grammar Translation Method's Effect on EFL Teaching And Learning
}

\author{
Aisha Ahmed Ali Hadi Al-Maamari, Airlangga University, Surabaya, Indonesia \\ Ali Mohammed Saleh Al-Hamzi, Airlangga University, Surabaya, Indonesia \\ Abdualrahman Nasser Saleh Al-Mamari, Undergraduate Student, Yemen
}

\begin{abstract}
In language teaching and learning, several methods are used for the effectiveness of teaching and learning. This research implemented the methods to assist the teacher in teaching the language, time after time. The methods have undergone many changes and development based on the attitude and school of thought for teaching and learning a language, so each method has different characteristics, techniques, and implementation. This reflection will expand on the grammatical translation method (GTM) used in the nineteenth century to teach English as a foreign language. This method is used based on the goal of grammatical competence. To achieve the goal, this method has several characteristics and techniques which will be used in its implementation. The writer attempts to do a review by investigating five published articles gathered from internet websites to show the use of the grammar-translation method, its effectiveness, and why it is criticized in the domain of teaching and learning English as a foreign language. The writer's reflection is also included.

Keywords: Grammar-Translation Method, EFL teaching, EFL learning, Translation.
\end{abstract}

\section{INTRODUCTION}

Language is essential in human life, so people cannot interact with each other without it. It is used as a medium that people use to express what they want to say of new feelings and ideas and explore the world. Language, by the way, is considered an essential part of our life, so using and learning it is very important for anyone on this earth. One of the most important languages that many people used is the English language because it is the most widespread language and the most appropriate language for learning and teaching all around the world.

Researchers have implemented some language teaching and learning approaches that teachers can use to impact teaching and learning activity. Depending on the condition and technological advancement, they are still adapting to the curriculum. There have been few theoretical foundations for language learning that underpin teaching methods for decades. Some of the language teaching techniques are the Grammar Translation Method, Direct Method, Audio Lingual Method, Total Physical Response, Silent Way, and others. The classical method, which focuses on grammar, translating texts, memorizing various vocabulary and conjugations, and performing written exercises, was taught in a foreign (Greek) foreign language (Douglas \& Frazier, 2001). The classic method became called the Grammatical Translation Method (GTM) in the nineteenth century. This technique was used to help students read and understand foreign language literature through studying the target language's grammar. The students would get to know the grammar of their native language, and that familiarity will help them speak and write

26 | IJET $\mid$ Volume. 10, Issue 1. July 2021

Copyright 2021 Aisha Ahmed Ali Hadi Al-Maamari, Ali Mohammed Saleh Al-Hamzi, and Abdualrahman Nasser Saleh Al-Mamari, are licensed under Creative Commons Atrribution-ShareAlike 4.0 International License. 
better in their language mother tongue (Larsen Freeman, 2000). GTM is a grammar mastery process that focuses on the grammar of the language. As Richards (2005) said, grammatical competence refers to knowing the rules that explain the ability to form a sentence.

This paper reviews notable published articles on the use of GTM in teaching and learning English as a foreign language by researchers in a variety of topics, with a particular focus on how these necessary studies demonstrate the effect of GMT on the performance of learners in learning of English as a foreign language. This analysis will enable both teachers and learners to recognize the utility of GTM in teaching and learning English as a foreign language. This study is also valuable for researchers because it opens the door to do some studies in the same domain.

Translation has a long tradition in teaching foreign languages as an educational method. With the introduction and advocacy of modern educational curricula at different times, it has passed through various stages. The use of Translation was derived from teaching in Latin and Greek and spread in Western Europe in the 18th and 19th centuries (Bowen et al., 1985). This curriculum originated at that time in Grammatical Translation (GM), which focused on learning the grammatical laws and vocabulary and translating the target language into their mother tongue (Machida, 2011).

The word target language used here denotes a second language taught or a foreign language (Larsen-Freeman \& Anderson, 2013). Since the grammar-translation method was commonly used in EFL classrooms, it was also criticized in terms of its focus on only literal and word-to-word fixed Translation between target and language and the mother tongue of learners and shortcomings in improving the development of communicative language students. In China, Chang (2004) represented what an English class dominated by the Grammar Translation Method looks like teacher-oriented were all class activities. Word-by-word and sentence-by-sentence reading materials were taught. Students were expected to recite appropriate grammar rules without any support for context and remember little word meanings through oral practice.

Dagilienè (2012) explained why foreign language teachers object to the use of Translation by asserting that Translation is related to the text and limited to only two abilities reading and writing; It is not a communicative task as it does not involve verbal interaction; It is a waste of time; It consists in using unwanted first language; It's boring to do and to correct (p.5). Richards \& Rodgers (2014) also indicated, close to Dagilienè's view, that he pays more attention to reading and writing than to improving his speaking and listening abilities. Stern (1999) also maintained that the translation method never emancipates the learners from the mother tongue's dominance. With these defects, the Grammar Translation Method started to give way to other methodologies such as the Direct Method, the Audio-Lingual Method, the Silent way, Desuggestopedia, Community Language Teaching (CLL), and Communicative Language Teaching (CLT). Although the Silent Method, Desuggestopedia, and Collective Language Teaching Method allow the required use of a first language or Translation in teaching, the role of the Translation will be much less or even reduced to zero as students make more and more progress in second language learning (Larsen Freeman and Anderson, 2013, Machida, 2011). However, when scholars began to emphasize the advantages and benefits of using pedagogy in Translation, changing and redesigning the translation system by introducing other methodologies, recent years have seen a revival of the translation method (Jiaoyan, 2015). Schäffner (1998), for example, identified six main advantages of using a translation practice:

1) Improve verbal ability

$27 \mid$ IJET $\mid$ Volume. 10, Issue 1. July 2021 Copyright 2021 Aisha Ahmed Ali Hadi Al-Maamari, Ali Mohammed Saleh Al-Hamzi, and Abdualrahman Nasser Saleh Al-Mamari, are licensed under Creative Commons Atrribution-ShareAlike 4.0 International License. 
2) Expanding the students' vocabulary in L2

3) Develop their style

The researcher also pointed out in Aqel (2013) experimental research on the impact of using the translation method on EFL learning that the process of Translation in the acquisition of foreign languages is more than the process of transferring meaning from the source language (SL) to the target language (TL)

It is an educational strategy that enhances the acquisition of four language abilities and helps English language learners understand a foreign language better and easier. Regarding the benefits of the translation method, most of them have been explained in general terms in both ESL and EFL learning environments, and a few scholars have outlined the different basics for using the translation method in two different study settings as well as delving into the factors that lead to some difference.

\section{METHOD}

The search was limited to entries, such as important papers, that could be accessed in unique fields. Each newly published selected journal and research literature is reviewed to identify studies regarding how English teaching and learning as a foreign language is positively and negatively affected by GTM. A total of 5 papers are divided based on the focus that introduces knowledge to those with great intentions to read from the five studies. The five articles are press papers that have been written. One of the effects of GTM on the teaching and learning of English as a foreign language is discussed in each journal. These effects and their implications for English teaching and learning as a foreign language have been briefly described.

\section{RESULT AND DISCUSSION}

The five studies are categorized based on their principal study interests, which span a massive field of subjects. And here, we are reviewing five published articles. Some of the distributed studies are presented to explain the topic to a specific perspective through the results. One of the effects of GTM on the teaching and learning of English as a foreign language is discussed in each report. The classifications and objectives of these selected studies, along with the author's reflection as for or against, can be illustrated as follows:

A study titled "Grammatical Translation in English as a Foreign Language Classroom in Thailand: A Look at the Words of an English Song" by Nantana Citirac (2015) was conducted in Thailand, where English has a foreign language status and is taught using a variety of methods, one of which is Translation Grammatical. The use of grammatical Translation is effective, successful, and famous and has been used today for several years now. This research was conducted to study the student's word choices in translating assigned words and translating them at the sentence level to help the student learn and develop his English and study and evaluate the problems that exist in his / her translation work. The results of the study showed that the student made mistakes and wrong translations, at the level of words and sentences, in their translation work, which is the Translation of preposition, pronoun, adverb, noun, as well as the relation of

28 IJET $\mid$ Volume. 10, Issue 1. July 2021

Copyright 2021 Aisha Ahmed Ali Hadi Al-Maamari, Ali Mohammed Saleh Al-Hamzi, and Abdualrahman Nasser Saleh Al-Mamari, are licensed under Creative Commons Atrribution-ShareAlike 4.0 International License. 
the pronoun, quantity, imperative and relative. Condition and by using the grammar-translation method among the target group, which includes 23 secondary school students. All these errors mean that at an early stage of their learning, more assistance should be provided to the Thai student to emphasize correct use and reinforce their use of English grammar and vocabulary, especially regarding problematic points. So it can be concluded that the grammatical translation method is still of interest in Thailand in English schools as a foreign language.

In the classes of the methodology of English as a foreign language in the twentieth century, the approach to grammatical Translation may have been criticized. If your goal is to read the language, it is beneficial for you to work with students who have been studying on collegelevel coursework and whose main challenge is the required reading in the last few years. But, grammatical Translation alone will not enhance the student's ability to speak, comprehend, or even compose or interpret very large texts in the target language, such as song lyrics. However, EFL learners graded well with passing translation exams in English as a foreign language class in Thailand, as long as they translate word for word, which is not entirely helpful when dealing with English song lyrics.

As mentioned earlier, English as a foreign language (EFL) is taught at all education levels in Thailand, while the traditional and official language is the central Thai language. Thus, teaching in Thailand is difficult for a Thai teacher, which is very difficult because the student's mother tongue is Thai, and the conditions surrounding them do not encourage them to use the English language in their daily lives. Hence, when teaching English to Thai students, such problems usually arise. What educational methods should be used? What is the level of English for my students? Do they have a small or large vocabulary bank? What language should be used as an educational medium, whether English or Thai or both? These questions usually come to a Thai teacher's mind, and we must find answers to these difficulties. A range of teaching methods are used to deal with difficulties to be effective in teaching English in Thailand, including the grammatical translation method; For some Thai teachers, while some may find it to be a traditional curriculum that serves only those purposes, this curriculum is still useful in assisting a student whose English language ability is at a low or beginning stage. With this technique, when students are taught and applied English grammar rules by translating English sentences into Thai, teachers can use the Thai language as a medium of instruction. However, it is often difficult for us teachers to help students achieve their academic and professional goals by using effective teaching methods to teach them English. The English language has a prominent place in the modern world. Accordingly, the researcher is interested in researching applying the English language class's grammatical translation method and anticipating the results to shed light on teaching methods and students' difficulties in using the English language. In the grammar category, the use of Translation appears to be limited to GTM, which is usually noncommunicative.

In the grammar category, the use of Translation appears to be limited to GTM, which is usually non-communicative. Traditionally, this approach uses the first language as a teaching tool, and the teacher who becomes the focus of the class does not have to be proficient in the second language. Also, grammar learning is performed deductively as students are required to memorize and practice grammar in exercises. Translating contextualized non-original phrases from L1 to L2 or vice versa is a typical practice in GTM. Emphasis is not placed on fluency but

29 | IJET $\mid$ Volume. 10, Issue 1. July 2021

Copyright 2021 Aisha Ahmed Ali Hadi Al-Maamari, Ali Mohammed Saleh Al-Hamzi, and Abdualrahman Nasser Saleh Al-Mamari, are licensed under Creative Commons Atrribution-ShareAlike 4.0 International License. 
structured accuracy (Zhou \& Niu, 2015).GTM is boring with all of these features (Scheffler, 2013) and is not designed to aid students in real-life settings for interaction in L2. Therefore, it is not shocking, as indicated by Celce-Murcia (2014), "that the result of this strategy is usually a reluctance on the part of students to use language to communicate."Thai students' ability to translate English songs showed that they have difficulty learning English, which is usually taught through the grammatical translation process. Based on the results of this report, based on translation work, Thai students made mistakes and wrong translations, both at the word and phrase level, i.e., translations of prepositions, pronouns, adverbs, and nouns, as well as uses of the referential pronoun, the quantitative subjunctive, precursor and relative. Therefore, it is important to promote Translation in language teaching/learning as an intermediate ability, rather than just an activity to find a linguistic equivalent across languages. In general, translation practice should aim at creating "functional" translations that fulfill the purpose of the communicative context and use the natural expressions of the target language. Using authentic communicative texts at the sentence level and beyond would make it possible to perform such tasks since they typically display semantic and pragmatic differences between L1 and L2. However, the translation things should be carefully tailored to the learners' language level so that they are not too difficult to translate (Salem, 2012).

Grammar Translation Method in ELT: Hindering The Development of Communicative Skills at Secondary Level" by Mazher et al. (2015) is another study carried out to show the GTM's effects on the development skills at secondary schools in Pakistan. The purpose of this study is to assess the communication skills of English language students who have been taught in Pakistan at the secondary level through the Grammar Translation Method (GTM).In GTM, there is usually no practice of listening or speaking. Pronunciation or any communicative aspect of a language is not given much attention. Reading and then only in the sense of Translation is the ability to be exercised. Examinations also consist of classical text translation. A questionnaire was used to gather data from Govt's 15 teachers. Faisalabad District Schools, who used this technique in schools. Quantitative data were analyzed by explaining the class note and the interview using a simple frequency count, percentage, and qualitative data. Data analysis reveals that GTM places more emphasis on learning English words, phrases and sentences, and structure patterns; But in a real-life context, the real use of the English language has failed. Even an entire English conversation cannot be conveyed by students studying through this technique at Pakistan's secondary school certificate level. It is proposed that teachers follow an ELT communicative approach to improve the students ' communicative ability.

In the early stages, at some level, you can translate while learning a new language. If you can incorporate it into a real-life experience of using language, getting to know the grammar is not a problem. Unfortunately, grammar is always taught in isolation from natural speech. Grammar can improve the learning process when taught with verbal phrases and sentences. There are many books on grammar to learn grammar and then grasp the language using fun and games with real-life examples. When studying languages, people suffer because they are not proficient in the language's fundamental processes and foundations. They study grammar, but with real practice, they do not understand it.

Similar conditions prevailed in Pakistan. Pakistani students teach grammar Translation Methods (GTM) in English at the high school level. In GTM, there is usually no practice of

30 $\mid$ IJET $\mid$ Volume. 10, Issue 1. July 2021 Copyright 2021 Aisha Ahmed Ali Hadi Al-Maamari, Ali Mohammed Saleh Al-Hamzi, and Abdualrahman Nasser Saleh Al-Mamari, are licensed under Creative Commons Atrribution-ShareAlike 4.0 International License. 
listening or speaking. Pronunciation or any communicative aspect of language is given little attention. Study results indicate that GTM placed greater emphasis on learning English words, phrases, and phrases, and structural patterns. But in real life, it has failed in the practical use of the English language.

Even a simple conversation in English cannot be conveyed by students who study in this way at high school qualification in Pakistan. It is suggested that teachers adopt a communicative approach to teaching English to improve learners' communicative ability.

Reading, writing, and Translation are the core capabilities that the grammatical translation curriculum promotes. This methodology has now been replaced by more methods that focus on using the language for communication purposes. Learning through speaking has a great appeal because you have to practice "boring" grammar in disguise. However, what is important is that you must learn it one way or another because language is made up of laws and structures. Some people (especially beginners) prefer explicit instructions. The more you progress, the more the meaning of new words and structures can be derived from the context.

Aql (2013) also conducted a study to research "The effect of using the grammatical translation method on the acquisition of English as a foreign language" to demonstrate the effect of using the grammatical translation method on acquiring English as a foreign language. This analysis is experimental. The study sample consisted of (20) male and female students in the tenth grade, all of whom were females from Al Mazar Governmental School in Jordan. The researcher used a random sampling method to conduct this research. The results of this study showed that the use of grammar and Translation as a foreign language by female students had a positive effect on the English language. This study concluded that female students taught using the grammatical translation method significantly advanced in grammar and gained greater selfconfidence. In order to overcome the problems of acquiring a second language, especially in grammar, this study recommends further research in the future in this area.

The author views the impact of the grammatical translation approach on learning English as a foreign language, based on this analysis's results positively. Some LDS researchers agree with the author; others disagree. Currently, second language learning is a global phenomenon. It is concerned with discovering appropriate methods to enhance the learning process. The problem causing strong contention among EFL researchers is: Will teachers only use a second language or a native language and a second language (i.e., Translation) in the classroom environment? Numerous studies have been conducted in which many results were found on whether or not Translation helps second language (L2) students develop their language skills. Some teachers consider using the first language (L1) in the L2 classroom environment seriously detrimental to learning the second language, while others suggest that teachers use it. And such discussions do not end with one final decision.

There is no magic way to get people to learn a language they don't need, in the authors' opinion. This grammatical translation approach is as effective in class as any other approach. It's also not much of a tool, but it's the way to use it. It can be more productive for a teacher with talent, commitment, and creativity than other teachers think. In many countries and institutions around the world, this teaching method is still prevalent. It continues to be attractive from an intellectual or linguistic perspective to those interested in languages. However, it does little to

$31 \mid$ IJET $\mid$ Volume. 10, Issue 1. July 2021 Copyright 2021 Aisha Ahmed Ali Hadi Al-Maamari, Ali Mohammed Saleh Al-Hamzi, and Abdualrahman Nasser Saleh Al-Mamari, are licensed under Creative Commons Atrribution-ShareAlike 4.0 International License. 
enhance your ability to use language for verbal communication.

Additionally, Buzorova (2018) conducted a paper titled "The use of the grammatical translation process in adult language education in foreign languages." In this article, the author discusses technologies that have lost their relevance in contemporary life. Today, most teachers of schools and other educational institutions are very vulnerable to applying this technology in their practices. The author assumes that this approach is most effective in teaching a foreign language to adults.

The grammatical translation method sometimes referred to as the classical method, is a traditional teaching technique used during the sixteenth century to teach Latin and Greek and was especially popular. The focus at the time was on translating texts and grammar and learning vocabulary by heart. Since Latin and Greek were taught more as academic subjects than as a means of oral communication, there was no emphasis on speaking and listening comprehension.

The issue is why the use of Translation in the class of English as a foreign language is still important. If we look at the past in the method of Translation, we can easily point out that it is the strong relationship between the method of Translation and the method of grammatical Translation that is highly criticized that leads to the prevention of the use of the method of Translation of English language teaching. In other words, individuals seem to view translation methods and grammatical translation methods as synonymous terms that are irrational and deceptive. While it cannot be denied that the translation grammar curriculum has been a popular method of teaching training with Translation, these two terms should not be understood equally. Therefore, it is assumed that while many scholars condemn the traditional method of grammatical Translation, the method of Translation itself has never been considered a flawed method of learning, and people's criticism and objection to the method of Translation simply focuses on the method of grammatical Translation. Another fact is also expressed in the fact that almost all the condemnations of the grammatical translation system or the method of Translation have focused on not focusing on the production of communicative language, leading individuals to ignore the usefulness of using this method in teaching and writing in the foreign language. The results of this study focused on the need to use translation methods in teaching literacy in foreign languages, especially in English as a foreign language where adults learn.

Another research conducted by Megawati (2017) was "Improving students' reading comprehension through the grammatical translation process," and the above. The purpose of the study is to improve students' reading comprehension through grammatical translation methods. The study was performed in the first semester at SMK Private Tapos Depok. Qualitative analysis, the review of separation procedures, is the type of research used by the researcher. Three cycles were used in the study. Four stages consist of each episode-planning, movement, evaluation, and thinking. The research was involved 33 students who were grade 10 students at SMK Private Tapos Depok. The researcher collected data using observation, interview, test, and discussion to collect the data you need at the study time. It determined the extent of the increase in students' reading comprehension before and after the following grammatical translation method.

Analysis of the study data showed that the average and percentage of students' grades improved, from the first cycle grade to 6.76 or 60 percent, the second cycle to 7.35 or 78 percent,

$32 \mid$ IJET $\mid$ Volume. 10, Issue 1. July 2021 Copyright 2021 Aisha Ahmed Ali Hadi Al-Maamari, Ali Mohammed Saleh Al-Hamzi, and Abdualrahman Nasser Saleh Al-Mamari, are licensed under Creative Commons Atrribution-ShareAlike 4.0 International License. 
and the third cycle to 7.80 or 100 percent. It can be seen that the grammatical Translation enhanced students' reading comprehension. It can be assumed that SMK Private Tapos Depok's 10th Grade Grammar Translation System in Academic 2016/2017 could improve students' reading comprehension.

The grammatical translation process increases the ability to read and translate something necessary for many learners to become familiar with the language. This technology has now been replaced by more communicative technologies, focusing on using the language for communication purposes. You may want to combine it with some communicative activity for the grammar-translation method to succeed, but that depends on your goals (and your students).

In the twentieth-century methodology of English as a foreign language, the Translation's grammatical method may have been criticized. If your goal is to be able to read the language, that is successful. GTM is said to be one of the standard methods used to teach a foreign language, but this technique focuses on grammar and word meanings and is not concerned with the pronunciation of words.

\section{CONCLUSION}

This study provides a summary of some selected studies conducted by researchers from all over the world from different geographical locations. The many topics give us a clear tone that a vital field of research is teaching and learning the English language. Among the five studies published, common themes related to the effect of GTM use on the teaching and learning of the English language were considered.

In their translation work, i.e., translations of the preposition, pronoun, adverb, and noun as well as the uses of the pronoun, the quantifier, the imperative, and the relative clause, in the semantics of errors and wrong translations produced by the student at both the linguistic level and the sentence level, it is evident when Thai students learn English using GTM in schools in Thailand or other regions around the world where English is taught as a foreign language.

A study of the data also indicates that GTM emphasizes learning English words, phrases, and patterns of structure. Still, in real-life situations, it fails to make practical use of the English language. Even a basic English conversation cannot be communicated by students who learn at the high school diploma level through this technology.

The beneficial benefits of using GTM in teaching and learning English are evident from the results of selected studies that demonstrate the effects of using the grammatical translation method on acquiring English as a foreign language or demonstrating the usefulness of GTM in the education of foreign adults.

The grammatical translation process increases the ability to read and translate something necessary for many learners to become familiar with the language. Many calls for replacing it with more communication approaches that focus on using the language for communication purposes exist. You may want to combine it with some communication activities for the sake of the grammatical translation method's success, but that depends on your goals (and your students).

33 | IJET $\mid$ Volume. 10, Issue 1. July 2021 Copyright 2021 Aisha Ahmed Ali Hadi Al-Maamari, Ali Mohammed Saleh Al-Hamzi, and Abdualrahman Nasser Saleh Al-Mamari, are licensed under Creative Commons Atrribution-ShareAlike 4.0 International License. 


\section{REFERENCE}

Aqel, I. M. (2013). The effect of using grammar-translation method on acquiring English as a foreign language. International Journal of Asian Social Science, 3(12), 2469-2476.

Bazarbaevna, B. L. (2018). The use of grammar-translation method in teaching foreign language for adults. Вопросы Науки и Образования, 2 (14).

Bowen, J. D., Madsen, H. S., \& Hilferty, A. (1985). TESOL techniques and procedures. Newbury House Pub.

Celce-Murcia, M. (2014). An overview of language teaching methods and approaches. Teaching English as a Second or Foreign Language, 4, 2-14.

Chang, Z. L. (2004). The pedagogical status of ELT in China: Challenges and issues. Journal of Language Teaching, Linguistics and Literature, 9, 35-51.

Dagilienè, I. (2012). Translation as a learning method in English language teaching. Studies about Languages, 21, 124-129.

Davies, A., \& Elder, C. (2004). The Handbook of Applied Linguistics Blackwell Publishing Blackwell Handbooks in Linguistics. Blackwell Handbooks in Linguistics, 17, 866. https://doi.org/10.1002/9780470757000.ch7

Douglas, D. A. N., \& Frazier, S. (2001). Teaching by Principles: An Interactive Approach to Language Pedagogy .: H. Douglas Brown. Wiley Online Library.

Jiaoyan, Y. (2015). Research on Application of Translation in English Teaching. 2015 Joint International Social Science, Education, Language, Management and Business Conference, 221-225.

Larsen-Freeman, D. (2000). Techniques and principles in language teaching. Oxford University.

Larsen-Freeman, D., \& Anderson, M. (2013). Techniques and principles in language teaching $3 r d$ edition-Oxford handbooks for language teachers. Oxford university press.

Machida, S. (2011). Translation in Teaching a Foreign (Second) Language: A Methodological Perspective. Journal of Language Teaching \& Research, 2(4).

Mazher, U., MUMTAZ, A., \& MEHWISH, A. (2015). Grammar Translation Method in ELT: Hindering the Development Of Communicative Skills At Secondary Level. Journal of Literature, Languages and Linguistics, 6, 65-72.

Megawati, M. (2017). The Improving Students' Reading Cmprehension through Grammar Translation Method. English Education: Journal of English Teaching and Research, 2(2), $95-108$.

Richards, J. C. (2005). Communicative language teaching today. SEAMEO Regional Language Centre Singapore.

Richards, J. C., \& Rodgers, T. S. (2014). Approaches and methods in language teaching. Cambridge university press.

Salem, I. (2012). L1-L2 sentence translation in classroom grammar tests. ELT Journal, 66(2), $147-155$.

Schäffner, C. (1998). Qualification for professional translators: Translation in language teaching versus teaching translation. Translation \& Language Teaching: Language Teaching \& Translation, 117-134.

Scheffler, P. (2013). Learners' perceptions of grammar-translation as consciousness raising.

$34 \mid$ IJET $\mid$ Volume. 10, Issue 1. July 2021 Copyright 2021 Aisha Ahmed Ali Hadi Al-Maamari, Ali Mohammed Saleh Al-Hamzi, and Abdualrahman Nasser Saleh Al-Mamari, are licensed under Creative Commons Atrribution-ShareAlike 4.0 International License. 
Language Awareness, 22(3), 255-269.

Stern, H. A., Kaminski, G. A., Banks, J. L., Zhou, R., Berne, B. J., \& Friesner, R. A. (1999). Fluctuating charge, polarizable dipole, and combined models: parameterization from ab initio quantum chemistry. The Journal of Physical Chemistry B, 103(22), 4730-4737.

Zhou, G., \& Niu, X. (2015). Approaches to language teaching and learning. Journal of Language Teaching and Research, 6(4), 798.

35 | IJET $\mid$ Volume. 10, Issue 1. July 2021 Copyright 2021 Aisha Ahmed Ali Hadi Al-Maamari, Ali Mohammed Saleh Al-Hamzi, and Abdualrahman Nasser Saleh Al-Mamari, are licensed under Creative Commons Atrribution-ShareAlike 4.0 International License. 